\title{
Editorial
}

\section{Una alternativa al primer discurso presidencial}

La juventud del nuevo presidente de El Salvador y de su equipo de gobierno así como la preparación académica de ambos - casi todos obtuvieron títulos de postgrado en universidades estadounidenses - ha levantado expectativas sobre las novedades que podría traer el tercer período de ARENA en la Presidencia de la República, las cuales se suman a las expectativas normales que todo nuevo gobierno suscita. Algunos gestos novedosos, un discurso más articulado de lo que es usual entre los políticos salvadoreños y las maneras suaves y educadas del nuevo presidente se han combinado para alimentar esas expectativas, hasta el punto de llegar a hablar de una renovación en las filas de ARENA.

Aunque el discurso de toma de posesión puede interpretarse como parte de la campaña electoral, por lo que tiene de promesa, o como un hecho irrelevante, por las circunstancias emotivas que lo rodean, también tiene mucho de programático. Al menos esa es la intención explícita de quien lo pronuncia. Las expectativas creadas por el cambio de gobierno, aun cuando el relevo tenga lugar entre miembros del mismo partido, alimentan la creencia de que pueden ocurrir cambios importantes. Por consiguiente, el primer discurso del presidente Flores es relevante desde esta perspectiva programática y de cambio. En este contexto cabe explorar dos cuestiones. La primera es su pertinencia, dadas las circunstancias por las que atraviesa El Salvador, y si no fuera pertinente, entonces, qué podría haberse dicho.

\section{Una transición de corto alcance}

El paso de una etapa a otra de la vida viene marcado por ritos, determinados por la costumbre y la tradición. El rito constata el paso de un antes a un después, expresa el significado de la transición y se convierte en su punto de referencia. La vida de las naciones no escapa a esta realidad de la naturaleza humana y también está jalonada por transiciones y sus ritos respectivos. El 
cambio de gobierno está marcado por la despedida del gobernante saliente y el recibimiento del que lo sustituye. El rito fundamental es la llamada toma de posesión. Por lo general, los ritos tienen una carga emotiva muy fuerte. En ellos, las emociones suscitadas a raíz del traspaso del umbral toman cuerpo. Las tomas de posesión no son una excepción y quienes participan en ellas se ven, necesariamente, sumergidos en símbolos cargados de emotividad.

Además de la emotividad, los ritos de paso son acompañados por una palabra, que explica la transición de una etapa superada a otra que aguarda, atractiva y desafiante al mismo tiempo. Es una palabra que da razón del paso y, por lo tanto, es una palabra oportuna y también relevante. Para conseguir su propósito no tiene por qué ser muy larga ni retórica, basta con que dé razón precisa de la transición. En una toma de posesión, esa palabra es el discurso del nuevo Presidente de la República y en cuanto éste debe dar cuenta del cambio de dirección, no puede ser pasado por alto.

La toma de posesión del presidente Flores fue impecable en cuanto se mantuvo fiel a la tradición, aun cuando el pueblo salvadoreño fue expresamente excluido. Sin embargo, la palabra que lo acompañó fue muy poco convincente y, en este sentido, el rito de transición quedó incompleto. Por lo tanto, criticar el primer discurso del presidente Flores es criticar la falta de una razón que debía dar cuenta del significado del rito y su emotividad.

Es innegable que el nuevo presidente se esforzó por dar razón de su gobierno. Se comprometió de manera solemne a construir una sociedad justa y a proporcionar una oportunidad a la igualdad, a crear empleo estable, a mejorar la educación y la salud, a reactivar el agro, a fortalecer la seguridad, a descentralizar el Estado, a promover la cultura, el arte, el deporte y la recreación, a proteger la familia, a mantener la solidez de la moneda y el cambio fijo, en una palabra, a retomar algunos de los puntos más relevantes de la agenda inconclusa que deja el gobierno de Calderón. Asimismo, insistió en la participación ciudadana, la responsabilidad compartida, el destino común de prosperidad y el protagonismo conjunto para la construcción del futuro, en síntesis, en la necesidad de establecer una gran alianza nacional para resolver los problemas más graves y urgentes de El Salvador. No obstante este esfuerzo por abrir horizontes y generar esperanza, Flores no convenció en su primer discurso como Presidente de la República.

Un gobernante no puede descartar el debate y la crítica sólo por ser negativos. Los actos gubernamentales contrarios al bienestar de la mayoría y del país entero deben ser denunciados por sí mismos. Parte de las tareas del gobernante es oír las críticas de los gobernados, con mucha mayor razón cuando aquél se considera cercano a éstos. 


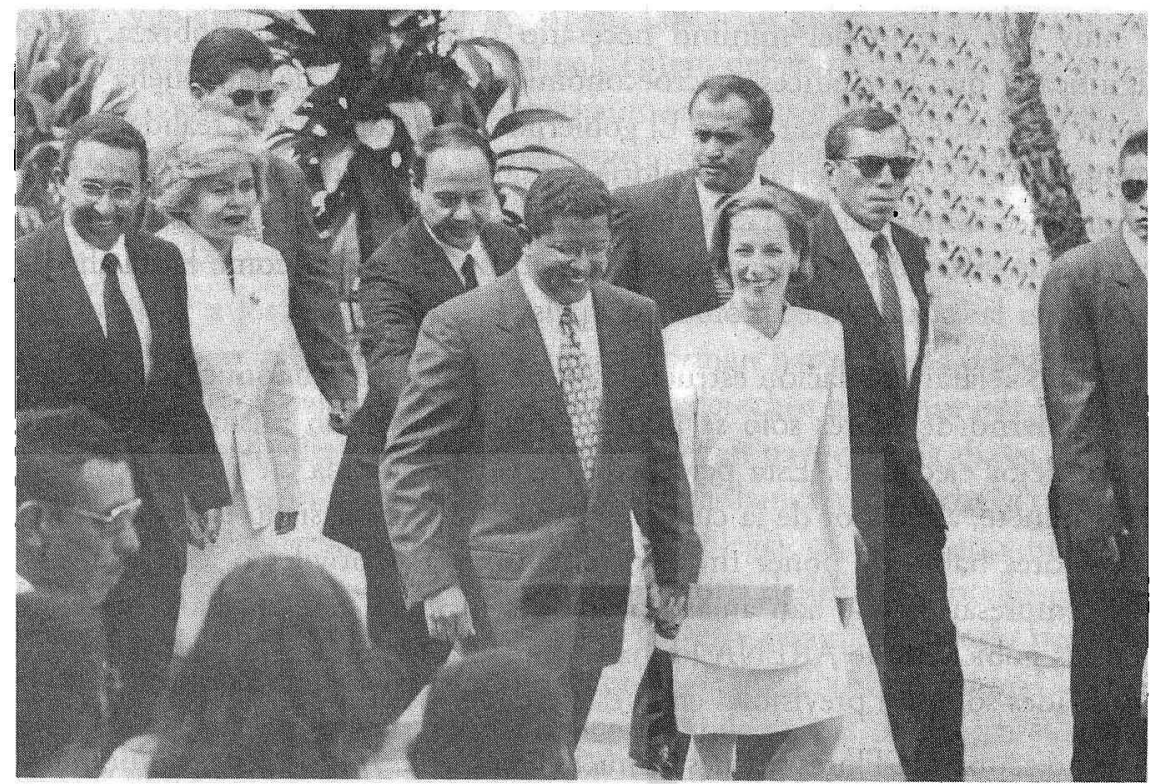

No convenció porque no estableció prioridades, porque no articuló las urgencias en un plan integral de acción y porque no relacionó éstas con los recursos financieros del Estado. Es cierto que no cayó en el lugar que sus predecesores en el cargo volvieron común y ya no se atrevió a afirmar que gobernaría para los más pobres, pero tampoco especificó cómo piensa impulsar la agenda social, al frente de la cual ha puesto a su gente de confianza y, por otro lado, a la más joven, manteniendo la política económica actual, sobre la cual no anunció cambio alguno y al frente de la cual ha colocado a funcionarios del gobierno anterior. Es evidente que con dicha política no se puede reactivar el agro, generar empleo estable, ni ampliar la cobertura y mejorar la calidad de los servicios de educación y salud, ni promover el desarrollo de la micro, pequeña y mediana empresa, ni mucho menos combatir la pobreza rural. Para hacer todo esto es necesaria una intervención gubernamental directa, firme y focalizada, y un papel más protagónico para las organizaciones de la sociedad, la cual va más allá de lo que los directores de la política económica están dispuestos a aceptar.

Una posibilidad no explicitada podría ser financiar esta agenda con los nuevos préstamos millonarios que El Salvador acaba de agenciarse en Estocolmo, a propósito del Mitch; pero con todo lo que ello pudiera suponer para un cambio social importante, al no abarcar entre sus objetivos una reforma estructural, sólo significaría ganar tiempo. Aun así, en el horizonte se cierne otra amenaza que el presidente Flores evadió: la recesión económica. The Economist, una fuente fuera de toda sospecha para los círculos oficiales y empresariales, ha predicho un crecimiento económico del 1.5 por ciento para este año, es decir, un crecimiento por debajo del cálculo del gobierno 
y muy por debajo del mínimo necesario para erradicar la pobreza. Esto significaría que los índices macroeconómicos no gozan de tan buena salud como se ha querido hacer creer. El gobierno no desconoce esta realidad, pero aceptarla de forma abierta equivaldría a reconocer su fracaso ahí donde más triunfos se adjudica. Su táctica parece ser ganar tiempo y esperar alguna especie de intervención maravillosa que permita continuar como hasta ahora, sin alterar la estructura económica del país.

Al no aclarar la relación estructural entre la política económica y la social, del gobierno de Flores sólo se podría esperar más de lo mismo, quizás un poco mejor ejecutado. Esta percepción se ve confirmada en la composición del gabinete, alrededor de la cual creó expectativas demasiado elevadas. Aunque Flores habló de poner fin al paternalismo y al privilegio, está rodeado por empresarios que han amasado grandes fortunas gracias a la protección que los gobiernos de ARENA les han brindado. De momento, entonces, las novedades sólo son previsibles en la esfera de lo social.

$\mathrm{Al}$ discurso de Flores le cuesta mucho centrarse. Comienza preguntándose "quiénes somos para poder vislumbrar hacia dónde vamos" y "cómo debe y podrá ser El Salvador del siglo XXI", pero sin dar una respuesta precisa. El mandatario divaga y se refiere, sin propósito definido, a los jóvenes, la existencia y el tiempo, el individuo y la sociedad, la necesidad de "concordia", y la libertad. Cuando, finalmente parece haber dado con el hilo conductor, los temas de la agenda nacional salen sin orden lógico: empleo, educación, salud, agua, descentralización, cultura, arte, deporte, recreación, familia, seguridad, macroeconomía, micro, pequeña y mediana empresa y agricultura. Otros temas igualmente importantes no fueron mencionados: corrupción, mujer e infancia, derechos humanos, medio ambiente, vivienda, tratados de libre comercio, integración regional y relaciones internacionales. Ciertamente, no se podía esperar un tratamiento detallado de cada uno de estos temas. Lo que se echa en falta es una visión articulada del país y su problemática, y de lo que el nuevo gobierno se propone hacer al respecto, en los próximos cinco años. Se podía esperar más de un presidente a quien se aprecia por su juventud y su formación universitaria.

Si el presidente Flores pretendía sentar las bases de su proyecto de alianzas amplias, reclamar a la oposición la esterilidad del debate que "no edifica" y la inutilidad de la crítica que "no propone y garantiza propuesta mejor" era algo fuera de lugar e incluso impertinente. Es gratuito achacar exclusivamente a la oposición una actitud no edificante, porque ARENA es tanto o más destructivo que aquélla. El compromiso ético que, en explicaciones posteriores, Flores dijo querer hacer con estos señalamientos debiera habérselo pedido primero a su propio partido. Semejante reclamo así como el aislamiento desde el cual Flores integró su equipo de gobierno no auguran nada bueno para la democratización de El Salvador. Un gobernante no puede descartar el 
debate y la crítica sólo por ser negàtivos. Los actos gubernamentales contrarios al bienestar de la mayoría y del país entero deben ser denunciados por sí mismos. Parte de las tareas del gobernante es oír las críticas de los gobernados, con mucha mayor razón cuando aquél se considera cercano a éstos.

No resulta fácil hacer alianza con un presidente que' promete "cuidar y sostener incólume" el legado de Cristiani y Calderón. Probablemente, se quiso referir a los acuerdos de paz, a la democratización del país y a la estabilidad macroeconómica; porque también forman parte de ese legado el encubrimiento de las violaciones masivas de los derechos humanos por parte de la Fuerza Armada dirigida por la "Tandona" y en particular la masacre de la UCA, la corrupción, la apropiación ilegal de la banca y de otros activos del Estado por parte de unos cuantos capitales privilegiados, los fraudes financieros y el empobrecimiento acelerado de la mayoría de los salvadoreños. Aceptar este legado de manera "incólume" es volverse cómplice, siendo parte de él. Al encabezar el tercer gobierno sucesivo de ARENA, es normal que el presidente Flores quisiera rendir homenaje público a sus predecesores, pero, en este punto, al no matizar o especificar, fue demasiado lejos.

El nombramiento de Mauricio Sandoval como director de la Policía Nacional Civil es parte del legado de Cristiani y Calderón que Flores se compromete a conservar. Sandoval fue encargado de comunicaciones del primero y espía del segundo, y cuenta con el respaldo de varias embajadas, entre ellas, la estadounidense y la española. Cualquiera que sea la misión encomendada al nuevo director de la policía, cualesquiera que sean las expectativas que se tengan sobre él y su trabajo, su nombramiento no sólo no está justificado, sino que hace muy difícil colaborar con un gobierno que contemporiza con

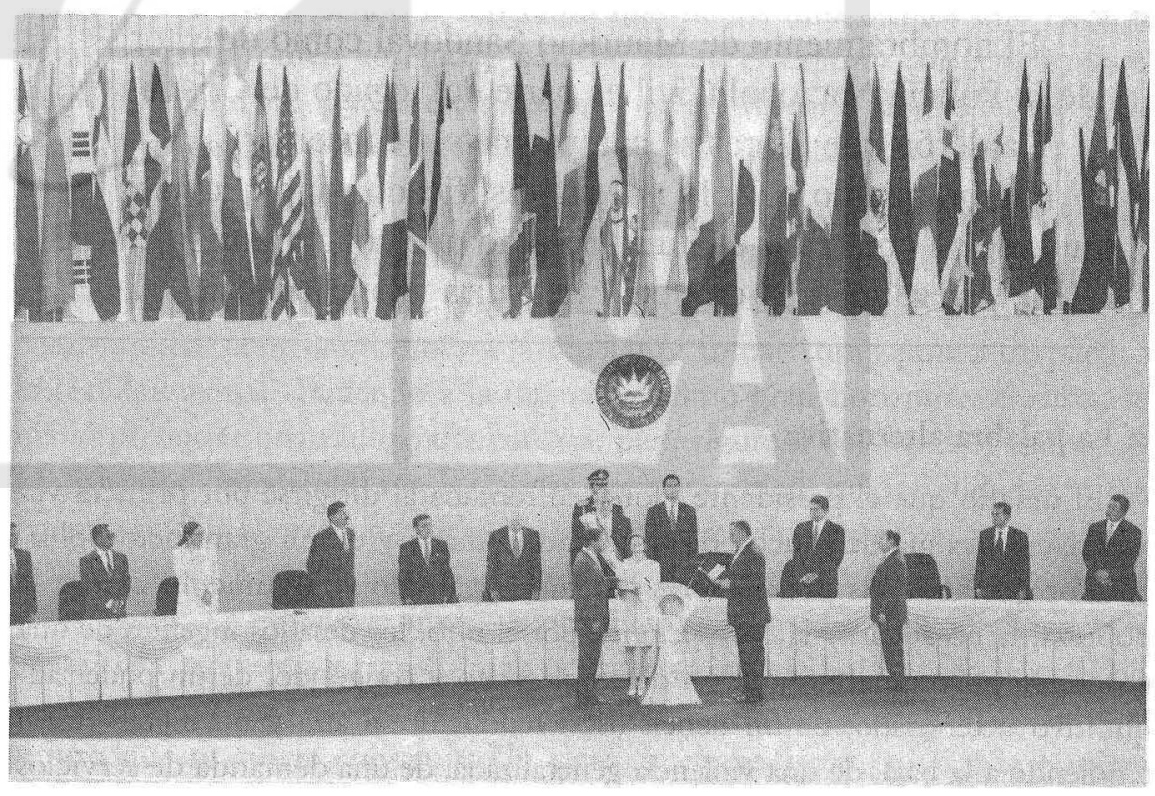


la ilegalidad, el crimen, la mentira y la injusticia. Sandoval no cumple los requisitos de ley para ocupar el cargo, no tiene experiencia policial, sino de inteligencia política, y fue responsable de una cadena nacional de radio que instigó a la masacre de la UCA, en noviembre de 1989.

Cuando la palabra que acompaña al rito exige rectificaciones posteriores, quiere decir que el mensaje no tuvo la claridad deseada. En efecto, Flores ha debido aclarar dos afirmaciones importantes de su primera intervención pública como presidente. La primera es que no pretendió lanzar un desafío a la oposición, sino hacer una respetuosa apelación para conformar una clase política mejor, capaz de garantizar una sociedad justa. El problema es que su auditorio, integrado por sus invitados, la inmensa mayoría perteneciente a las clases altas o a los círculos de poder, no lo entendió así. Y el mismo director de la policía se defendió de los primeros cuestionamientos sobre sus antecedentes esgrimiendo las afirmaciones de Flores. La segunda rectificación vino por el lado de la moneda. Las palabras de Flores apuntaban a la dolarización, pero ahora resulta que sólo se referían al compromiso de mantener la solidez de la moneda salvadoreña.

El primer discurso del presidente Flores es decepcionante. De sus proposiciones no se puede esperar razonablemente que al cabo de sus cinco años como Presidente de la República, ésta sea más justa y solidaria. Su palabra no estuvo a la altura de las circunstancias. No pudo dar razón de la transición, dejando en emotividad de espectáculo grandioso lo que era una oportunidad única para dar cuenta de lo que su gobierno pretende representar para las mayorías salvadoreñas.

El nombramiento de Mauricio Sandoval como director

de la Policía Nacional Civil es parte del legado de Cristiani y

Calderón que Flores se compromete a conservar [...] su

nombramiento no sólo no está justificado, sino que hace

muy difícil colaborar con un gobierno que contemporiza con la ilegalidad, el crimen, la mentira y la injusticia.

\section{La palabra alternativa}

El desafio que el presidente Flores enfrentaba al dirigirse por primera vez a la nación exigía de mucha profundidad humana y de un gran tacto político. Por un lado, sus predecesores habían desgastado el argumento contra la pobreza, la ilegalidad y la corrupción y, por el otro, los desafios ingentes de una economía poco dinámica, de un desempleo alto y congelado, de un poder adquisitivo deteriorado, de un déficit fiscal tendiendo al alza y un ingreso fiscal tendiendo a la baja, de una violencia generalizada, de una demanda de servicios 
públicos cada vez más insatisfecha, a todo lo cual hay que agregar las presiones provenientes de las esferas del poder político y económico, le habrían dejado muy poco espacio para maniobrar. Pero aun reconociendo la incidencia de estas variables, cabe ensayar, a modo de propuesta, cuál pudiera haber sido el primer mensaje de Flores a la nación al asumir la. Presidencia de la República.

El primer mensaje del nuevo presidente debiera haber propuesto como gran meta integradora de su gestión gubernamental el dar esperanza a un pueblo salvadoreño agobiado por el deterioro de su nivel de vida, que incluye un medio ambiente cada vez más hostil, y por la amenaza constante a su integridad y, además, desencantado de la política y escéptico ante las promesas de cualquier gobierno. Ante tanto pesimismo por la falta de horizonte y el engaño repetido, lo más apropiado hubiese sido que el presidente Flores diera cuenta de su propia esperanza como gobernante, como político y como persona, es decir, podía haber compartido con la nación las razones por las cuales piensa que El Salvador tiene futuro y que él y su gobierno constituyen la alternativa mejor para aproximarlo.

Dar cuenta de la esperanza es dar cuenta del futuro, pero a partir de una realidad presente, cuyas limitaciones estructurales imposibilitan su concreción histórica, pero también la reclaman con fuerza. Dar cuenta de la esperanza es dar cuenta del presente, pero para superarlo, actuando transformadoramente sobre él, desde la realidad futura que se busca actualizar. La afirmación implícita del futuro sólo puede ser concretizada superando la negación también implícita del presente. Cuanto mayor es la contradicción entre el presente y el futuro, la esperanza se vuelve más profunda y determinada. Por lo tanto, siendo la esperanza uno de los dinamismos más eficaces para superar el orden antiguo y para poner en el camino correcto hacia el nuevo, no sólo no puede estar ausente en un discurso como el del 1 de junio, sino que ella debía constituirse en su gran horizonte.

En lugar de recorrer una lista más o menos larga y ya de sobra conocida de las áreas de trabajo, prometiendo breve y genéricamente qué hará el gobierno en cada una de ellas, porque ni el lugar ni el tiempo permiten otra cosa, hubiera contribuido más a la esperanza tomar como punto de partida la realidad actual. Teniendo a la esperanza como gran horizonte, el discurso debió presentar una radiografía concisa, pero rigurosa del estado presente de El Salvador, señalando sus fortalezas, pero también sus debilidades y sus amenazas. Sin ahorrar la crudeza de sus reclamos y urgencias, no por afán masoquista ni para ahondar el pesimismo, sino para señalar con objetividad los desafíos. La esperanza invita a introducirse en medio de la realidad presente para renovarla y transformarla desde sus raíces. Sólo desde la realidad que ha de ser negada y superada es posible avanzar con seguridad hacia el futuro que se quiere construir. Un ejercicio de realismo como éste hubiera 
permitido constatar al mismo tiempo cómo recibe El Salvador y dónde se propone dejarlo, al cabo de los cinco años de gestión presidencial.

Iniciar una gestión presidencial presentando el estado de la nación que se recibe puede resultar demasiado fuerte, porque podría ser interpretado como una crítica abierta a lo que el presidente saliente hizo mal o dejó de hacer. Sin embargo, una salida intermedia, sin ser la ideal, podría dar cuenta parcial de esta dificultad. Dicha salida consiste en explicar el por qué de cada una de las áreas mencionadas en el discurso e imponerse metas concretas y, por lo tanto, evaluables, por ejemplo, anualmente, cuando el poder ejecutivo acude al legislativo a informar sobre su gestión. Pero si de algo peca la política salvadoreña es de su falta de realismo. Por lo general se prefiere la ambigüedad cuando no la fantasía, que ofrecen un espacio más amplio para la maniobra, y lo que es peor, el engaño sin pudor alguno con el cual los políticos intentan disimular sus intereses egoístas. El realismo, en cambio, al retenerlos en la realidad misma, los obliga a atenerse a ella y a tener que actuar sobre ella. De esta manera, el realismo los convierte en servidores de la realidad.

La esperanza sólo surge de la realidad concreta, aun cuando ésta sea más negariva que positiva. No es posible generar esperanza dejando de lado la realidad. Por supuesto, se puede intentar generar esperanza sin enfrentar la realidad en toda su crudeza, pero, a la larga, sobre todo en la política, ésta se acaba imponiendo. Las mayorias no pueden vivir de ilusiones y engaños eternamente. Es lo que le ha pasado, en gran medida, a la política salvadoreña. Ante una realidad que no experimenta las transformaciones repetidamente prometidas, la reacción normal es el escepticismo. Para combatirlo sólo hay un medio, volver a la realidad nacional.

El primer mensaje del nuevo presidente debiera haber propuesto como gran meta integradora de su gestión gubernamental el dar esperanza a un pueblo salvadoreño agobiado por el deterioro de su nivel de vida, que incluye un medio ambiente cada vez más hostil, y por la amenaza constante a su integridad y, además, desencantado de la política y escéptico ante las promesas de cualquier gobierno.

Esta vuelta es crucial para crear confianza y credibilidad en un gobierno que, como el de Flores, es tan poco representativo - no hay que olvidar que sólo captó el voto del 18 por ciento de la población en edad para votar- y que, por otro lado, se propone como eje fundamental de su gestión establecer alianzas amplias con la población. Es evidente que la colaboración de ésta con las autoridades de seguridad y policía es clave para combatir la violencia y en particular la delincuencia. Más aún, el acercamiento de la policía a la 




comunidad y la colaboración de ésta con aquélla es el punto crítico del plan de seguridad del gobierno de Flores, pero es, al mismo tiempo, su mayor debilidad, por la falta de confianza y credibilidad en este gobierno y en cualquier otro gobierno salvadoreño que se mantenga tan alejado de las realidades sociales del país. Las posiciones ahora tan lejanas podrían aproximarse si la población en su conjunto, pero en particular las mayorías populares percibieran que el gobierno de Flores tiene una preocupación genuina por su bienestar.

De ahí que el bien común y en particular el de la mayoría de la población es un tema de vital importancia, que tampoco debiera estar ausente en el primer discurso de un Presidente de la República. De hecho, el estado de la nación no es más que el estado del bien de lo que es de todos. El Presidente de la República está obligado, por lo tanto, a comprometerse a luchar por la cobertura y consolidación de ese bien y en contra de quienes se lo apropian indebidamente u obstaculizan su concreción histórica. No hubiera estado de más, entonces, que el presidente hubiera recordado a la nación la primacía de este bien sobre cualquier otro y su obligación de velar por él. Un presidente que contara con un apoyo sólido de parte de su partido y de la población podría incluso ir más allá y pasar de los principios a las aplicaciones y señalar dónde se encuentran las resistencias para que ese bien sea verdaderamente común.

Establecidos los aspectos anteriores, el mensaje presidencial podía haberse orientado a animar a la población a participar en las tareas importantes del nuevo gobierno. El éxito de este llamado depende de cuánta credibilidad y confianza pueda despertar el Presidente de la República. Ambas son requisito 
indispensable para una participación general, entusiasta y efectiva. La claridad y la concreción del mensaje y sobre todo el carisma personal del mandatario tienen una importancia capital para convocar a la sociedad alrededor de una tarea común. Ciertamente, el presidente Flores hizo este llamado, pero no convenció. No sería aventurado afirmar que sus palabras cayeron en el vacío. Les faltaron realismo y credibilidad. La sociedad salvadoreña ya está acostumbrada a estas invitaciones que los políticos le hacen con cierta periodicidad. Ambos saben bien que no es más que un tópico de moda del discurso público.

Tener como horizonte del gobierno y de cada una de sus dependencias el bien común y establecer planes y metas concretas, daría coherencia y sentido a toda la actividad gubernamental, por modesta que ésta pueda ser.

Una invitación de esta clase para ser seria y tener eco exige, primero, que quien la haga esté convencido de la necesidad y del valor del aporte de sus invitados $\mathrm{y}$, segundo, que interpele directamente a los actores de la vida nacional. En este sentido, habría que haber invitado a toda la población a colaborar con la policía, pero también habría que haber exhortado a esta última a servir y respetar a aquélla, a mejorar su trabajo, a ser escrupulosamente honesta y respetuosa de las leyes. Habría que haber interpelado a la banca para que, junto con el gabinete económico, revisasen la orientación del crédito, el nivel de las tasas de interés y la rentabilidad racional que debieran esperar. Habría que haber animado a los empresarios a invertir en el desarrollo industrial del país, pero ofreciéndoles incentivos reales y exigiéndoles, al mismo tiempo, eficiencia productiva y administrativa. Habría que haber exhortado con vehemencia a todos, pero de manera directa a los más ricos, a pagar de manera cumplida y fiel sus impuestos respectivos; pero al mismo tiempo habría que haber exigido a la burocracia estatal una mayor eficiencia e impuesto un severo régimen de austeridad. Habría que haber hecho un llamado urgente para rescatar el medio ambiente salvadoreño o al menos para detener su deterioro acelerado, identificando los desafíos técnicos y las resistencias sociales.

Supuesto todo lo anterior, el primer discurso del Presidente de la República debiera haber identificado cuáles son las metas de su gobierno a corto, mediano y largo plazo. Las metas deben ser realistas, es decir, no prometer aquello que, de antemano, sabe que no podrá cumplir. No debiera prometer lo que no está dispuesto a conceder ni lo inalcanzable, por no ser viable. Simultáneamente, el presidente podía haberse comprometido a evaluar de forma periódica el desarrollo de su gestión de acuerdo con estas metas, con- 
trastando promesas contra resultados. Por eso, las metas deben ser lo suficientemente concretas como para ser medibles. Este compromiso es importante porque deja poco espacio para la ambigüedad y la incompetencia y porque, al mismo tiempo, contribuye a demostrar de forma palpable que el avance es posible. Entonces, los logros alcanzados se convierten en aliciente para profundizar y consolidar el proceso así como para contar con la aprobación y la participación popular. Y los fracasos debieran ser explicados, atribuyendo responsabilidades. Esto, en lugar de socavar la gobernabilidad, tal como comúnmente se cree, aumentaría la credibilidad del gobierno y reforzaría su capacidad ejecutora de una manera inusitada.

Aquí lo determinante no es tanto el alcance de los logros, como la dirección de la gestión o del proceso mismo. Tener como horizonte del gobierno y de cada una de sus dependencias el bien común y establecer planes y metas concretas, daría coherencia y sentido a toda la actividad gubernamental, por modesta que ésta pueda ser. Creer en las bondades y posibilidades del propio proyecto de nación, esperar realmente que el país puede llegar a estar y ser mejor y entregarse de lleno a conseguirlo es el primer paso para que la sociedad también comience a compartir la misma creencia y la misma esperanza y para que se decida a tomar parte, poniendo al servicio de tal proyecto sus mejores talentos y entregando la elevada cuota de sacrificio que estas grandes empresas suelen requerir.

Estos elementos son esenciales para que un discurso presidencial sea también una manifestación de liderazgo. El liderazgo es necesario para asentar con firmeza las bases del nuevo gobierno y para generar confianza en la nueva conducción del país. Un Presidente de la República como el que las alianzas de Flores perfilan debe tener una capacidad muy grande para aglutinar a la mayoría de las fuerzas sociales del país alrededor de un proyecto que se propone alcanzar la prosperidad y el bienestar de las mayorías salvadoreñas, un proyecto que aquéllas deben apropiarse como suyo, lo cual supone que en éste debe predominar el bien común donde todas puedan reconocerse, al menos parcialmente, y la renuncia explícita, incluido el mismo partido oficial, a proyectos o agendas particulares, por lo menos en aquello que contradiga a aquél. Todo esto exige que el Presidente de la República esté dotado de cualidades personales excepcionales para dialogar y convencer, negociar y avanzar, entusiasmar y comprometer.

Las cualidades pedidas a quien asume la conducción de este proceso son muy exigentes, pero no puede ser de otra manera, dada la meta que se ambiciona, el bienestar del pueblo salvadoreño. La transformación radical de unas estructuras injustas por otras justas y la superación de una cultura de la violencia por otra de la paz demandan un liderazgo audaz y valiente, dispuesto a romper los moldes tradicionales y a abandonar los caminos trillados. Un cambio tan radical sólo es posible con el apoyo decidido y masivo del pueblo. Por lo tanto, un presidente de derecha como Flores debe superar 
el temor ancestral —cuando no el menosprecio- a las mayorías populares. No es suficiente conocer sus necesidades de primera mano, sino que además hay que creer en ellas, abrirles espacios reales para que se organicen y darles poder para que expresen sus ideas e impulsen los cambios. Un presidente de izquierda tendría que enfrentar las tentaciones del populismo y la instrumentalización de las masas. En cualquier caso, sin el apoyo popular, el cambio del país es empresa menos que imposible.

\section{El primer discurso del presidente Flores no estuvo a la altura de las circunstancias de El Salvador. No fue material lo que le faltó, sino la perspectiva.}

Finalmente, pero no por eso menos importante, en El Salvador actual, un primer discurso presidencial tiene forzosamente que insistir en la dimensión ética de la gestión gubernamental y de la sociedad entera. En un país donde la ética no es una dimensión que se tome en consideración en las decisiones públicas y privadas, un Presidente de la República no puede pasar por alto su primera intervención sin recordar sus principios básicos. El recordatorio debe evitar, sin embargo, el discurso abstracto y el tono magistral y hablar desde la inmoralidad predominante. No se trata de hacer del presidente un predicador moralista, sino de que éste aproveche esa ocasión única para señalarle a la sociedad las inmoralidades del quehacer público y las correcciones que, en consecuencia, deben introducirse.

Desde esta perspectiva, el discurso sobre la moral pública debe enfatizar la necesidad absoluta del derecho, pero no debe conformarse con él; sino que debe ir más allá e insistir en los valores universales, consagrados en la Declaración Universal de los Derechos del Hombre y en las otras declaraciones de Naciones Unidas que la complementan. Es así como no podrían dejar de mencionarse algunas de las faltas más corrientes contra la moral pública como el desprecio a la vida humana, la indiferencia ante la dignidad de las personas, la práctica generalizada de la corrupción y la mentira oficial, que encubre estas violaciones y garantiza la impunidad de sus responsables. Ante ello, el Presidente de la República debiera comprometerse a promover el aprecio a la vida humana y el respeto a la dignidad de todos los salvadoreńos y extranjeros que se encuentren en el territorio nacional, a combatir la corrupción, a reforzar el control sobre la gestión gubernamental -en particular en aquellos sitios donde más se practica la corrupción-, a dar y pedir cuentas y a esforzarse por decir la verdad sobre el país y su gobierno, incluyendo sus acciones y sus funcionarios. Dada la crisis por la que atraviesa El Salvador, su presidente debiera convertirse en un punto de referencia obligado del derecho y la moral pública y privada. 
El primer discurso del presidente Flores no estuvo a la altura de las circunstancias de El Salvador. No fue material lo que le faltó, sino la perspectiva. Por un lado, mantuvo el formalismo tradicional, típico de esta clase de discursos, dejando pasar así una oportunidad única para innovar, en un momento determinante de la vida de El Salvador. Por la otra, la visión del país y de su gobierno desde la cual fue redactado es equívoca. Todo esto puede atribuirse al descuido o a la incapacidad, que sería lo menos grave; pero también podría obedecer a una intención deliberada, o ambas cosas, lo cual, obviamente, sería muy serio y preocupante. Quienes defienden al presidente Flores alegan la emotividad del momento o piden los cien días usuales para demostrar sus buenas intenciones, su capacidad para dirigir el país y para hacer las cosas bien. Hay que aceptar que ambos argumentos contienen puntos a su favor, pero al mismo tiempo es preciso reconocer que el discurso del presidente Flores pudo ser más realista, verdadero y esperanzador.

El vacío más notable de su planteamiento es la ausencia de razones para esperar que la sociedad salvadoreña sea más justa y solidaria bajo su conducción. La construcción de una sociedad justa que Flores propone como tarea de los próximos cinco años de su gobierno es algo pretenciosa; bastaría con que se esmerara en colocar sus cimientos. Pero, entonces, tendría que cambiar su discurso. 